\title{
Itinerario del héroe barroco: de Virgilio Malvezzi a Josep Romaguera
}

\author{
JoRGE GARCAA LOPEZ \\ (Universidad de Gerona)
}

La biografía constituye un género fundamental de la prosa culta seicentista. El mismo Baltasar Gracián comenzó su carrera literaria escribiendo biografías. El héroe (1637), El polftico (1640) y El discreto (1646) constituyen tres biografias que nos recuerdan hasta que punto el género conforma uno de los elementos estructurales básicos de su prosa. En El discreto, incluso, una biograffa ideal cierra sus primores como en una suerte de microcosmos que retrata al héroe gracianesco, esquema que se reproduce en $E l$ criticón en las cuatro estaciones de la vida humana. El origen de la literatura gracianesca presupone, pues, como capítulo preliminar, situar esa biografía en el horizonte de su época.

El caso es que escribir biografias no era ninguna novedad. Durante la primera mitad del siglo XVII es uno de los generos literarios más importantes desde principios de los años treinta del siglo XVII constituía una moda entre los escritores cortesanos de Madrid, tales como Diego de Saavedra Fajardo o Francisco de Quevedo. En el caso de Saavedra Fajardo, la biografía del político ideal está en la base de su obra fundamental, las Empresas políticas, lo que le permite un recorrido por los diferentes momentos de la vida de un príncipe, comenzando por su educación a partir de la Política de Aristoteles ${ }^{2}$. Sin embargo, el primer esbozo de las Empresas políticas lo constituye su obra Razón de Estado del rey catolico don Fernando, terminada a finales de enero de 1631, que permaneció inédita en su época, y que no es otra que una biografía política del rey aragones ${ }^{3}$. Pero también la biografía es la base literaria de Corona gotica, una historia política de los reyes godos donde cada reinado se narra en términos biográficos y se valora su eficacia. Como en el caso de $E l$ criticón, el funda-

I El estudio fundamental sobre la prosa biografica barroca sigue siendo la obra clásica de E. Ferrari, Fernando el Catolico en Baltasar Gracian, Espasa, Madrid, 1945.

2 S. Lopez Poza, ed., D. de Saavedra Fajardo, Empresas políticas, Cátedra, Madrid, 1999.

3 A. Blecua y J. Garcia López, Intraducciones a la poltetca y Razón de Estado del ney catolico don Fernando, Asociación de Biblibfilos, Barcelona, 1984, y J. Garcí López, *Quevedo y Saavedra: dos contornos del seiscientosw, La Perinola, 2 (1998), pag. 237-260. 
mento de la biografía se basa en la idea del hombre natural, recogido de forma explícita de la Germania de Tácito. Pero si de Saavedra volvemos la vista a Francisco de Quevedo, nos encontramos con lo mismo, especialmente en El Rómulo (1632) y en su Marco Bruto. En el Madrid de los años treinta del siglo XVII, los principales escritores de vanguardia frecuentan la biografía. El caso de Quevedo nos permite tirar del hilo. El Rómulo es una traducción de Il Romulo que el marqués Virgilio Malvezzi había publicado en Bolonia tres años antes. Centrar nuestra atención en esa obra singular nos conduce a Baltasar Gracián.

La biografía histórica escrita en una prosa culta lacónica, en efecto, parece haberla puesto de moda Virgilio Malvezzi a finales de los años veinte del siglo XVII con su primera biografía Il Romulo, lo que delata, simplemente, la exitosa recepción de su obra, multiplicada rápidamente en los principales idiomas europeos, incluyendo el latín, y con más de veinte ediciones hasta finales de siglo en Italia o fuera de ella ${ }^{4}$. Virgilio Malvezzi era originario de una rancia familia proespañola de Bolonia, pero eso nos explicará pocas cosas, aparte de su familiaridad con la corte de Madrid o el olvido literario de su obra'. Más productiva es la constatación de que una de las vivencias básicas de su juventud sea la Roma de Urbano VIII, uno de los centros más innovadores y dinámicos de la Europa de principios del siglo XVII, y donde Galileo Galilei pugna por rehabilitar a Copérnico. Se puede seguir con algún detalle su peripecia en la Roma de principios de los años veinte, donde el marqués era asiduo asistente a la Academia dei Deseosi, y una de sus jóvenes estrellas, junto al enfant prodige Sforza Pallavicino. Entre los Deseosi sabemos que por lo menos una vez Il saggiatore habla sido propuesto como tema literario y de disputa ${ }^{6}$. Por otra parte, estaba en íntima relación con los principales colaboradores de Galileo en Roma, y por lo que se trasluce en algún que otro epistolario conservado, apoyaba al partido de los Lincei ${ }^{7}$. Por ahí comenzamos a sospechar que el impulso inicial de su obra se articula sobre una propuesta estética muy cercana al círculo de Galileo. Quizá por ello nos encontramos en su obra un continuado elogio de las matemáticas:

Diceva un sabio che Dio z geometra forse, perche il mondo consiste di proportione più geometrica che aritmetica

4. Bozza, Scrittori politici italiani dal 1550 al 1650, Edizioni di Storia e Letteratura, Roma 1980 (1 $1^{*}$ ed. 1949), págs. 163-164; antes de mediar el siglo está traducido a las principales lenguas europeas: tres en inglés (desde 1638), en castellano, en francés (desde 1645) y en latín (ya en 1636). Solo las fechas que nos da Bozza, aunque incompletas, nos permiten valorar cómo Quevedo se adelanta a todos los traductores europeos. Su importancia está recogida en ocasiones en la bibliografia; cfr. J. A. Maravall, La cultura del barroco, Ariel, Barcelona, 1975, pág. 421.

3 Para la biografia de Malvezzi, véase R. Bründli, Vingilio Malvezzi, politico e moralista, Tipografia dell'USC, Basilea, 1964 y E. Belligni, Lo scacco della prudenza. Precettistica politica ed esperienza storica in Virgilio Malvezzi, Olschki, Firenze, 1999.

6 P. REDondi, Galileo heretico, Alianza, Madrid, 1990, págs. 91 y 219.

7 Virgilio Malvezzi aparece en intima relación con los amigos de Galileo en la correspondencia entre Guiducci y Galileo; Véase W. R. Shea y M. Artigas, Galileo en Roma. Crónica de 500 dias, Encuentro, Madrid, 2003, págs. 127.

B V. Malvezzi, Il Romulo, Clemente Ferroni, Bolonia, 1629, pág. 24; Quevedo traduce: *deźa un philósopho que Dios era geómetra, quizá porque el mundo consiste en proporción más geométrica que arismética» (C. Isasi, ed., F. de Quevedo, El Rómulo, Universidad de Deusto, Bilbao, 1993, pág. 55). 
Una primera lectura de la cita nos recuerda el idealismo matemático de la tradición pitagórica o platónica. Su atenta consideración, sin embargo, conduce rápidamente a la evidencia de que ese philosopho al que se está aludiendo en pasado (Diceva un philosopho) no es otro que Galileo Galilei, puesto que --como quien no quiere la cosa - se enuncia una de las doctrinas fundamentales de Il saggiatore: que el lenguaje de la naturaleza son las matemáticas. No olvidemos que detrás de Il saggiatore hay una estética y unos círculos literarios que apuestan por los estilos modernos en detrimento del mero seguimiento de la tradición. Esos círculos y sus exigencias estéticas están también en el origen de Il saggiatore (1623) ${ }^{9}$, y probablemente con esos momentos de tensiones y polémicas en la Roma de principios de los años veinte se corresponden los Discorsi sopra Cornelio Tacito. Por otra parte, no olvidemos tampoco que la citada expresión ronda la herejía después de mayo de 1633, cuando Galileo es obligado a abjurar de sus doctrinas, puesto que de la identidad entre física y matemáticas - idea incluida en la cita, junto a la precedencia de la geometría - se deducía por entonces con facilidad la doctrina copernicana. En todo caso, la cita nos enseña hasta qué punto el laconismo romance no es mero jugueteo estilístico, sino una poetica de la prosa alineada con las principales novedades de su tiempo. Eso es precisamente lo que nos encontramos en II Tarquinio superbo, donde ahora es el estilo lacónico el que está descrito en términos matemáticos:

El dar preceptos a los príncipes para reinar bien es empeño que toca en bizarría, si bien es sobradamente costoso, y estoy por decir soberbio. Son por la mayor parte ideas, cuyo ser reside en el entendimiento, fuera del cual no tienen subsistencia alguna; son formas deseadas, y por imposible no conseguidas. Un punto que en abstracto se figura indivisible, en concreto se divide en muchas partes, y se puede dividir infinitamente, y asi juzgo de más conveniencia a obra tal los ejemplos que los preceptos ${ }^{16}$

Junto a este tipo de expresiones, encontramos comparaciones musicales - ha nacido el melodrama, y Malvezzi es contemporáneo de Monteverdi - y recuerdos de los avances científicos de la época (la filosoffa magnética, el problema de la latitud geográfica, etc.), sin olvidar el recuerdo de las manchas solares («I difetti del Sole, che si additano con sicurezza riflessati nell'acque, non si mostrano a diritto nel cielo senza pregiuditio de gl'occhi" "), elementos que refuerzan nuestra conclusión: el origen del laconismo romance constituye un intento de construir un clasicismo literario puesto al día. Sensación muy notable, además, en la bellísima edición príncipe de $I$ Romulo que estampo Clemente Ferroni, encabezada por una lamina donde un sabio contempla el sol reflejado en una laguna, probablemente observando, como nos dice la última cita, las manchas solares; precioso emblema

9 Lo recuerdan W. R. Shea y M. Artigas, ob. cit., pag. 111.

10 Las citas de $I$ Tarquinio superbo catan tomadas de Obras del marqués Virgilio Malvezzi, Lisboa, Paulo Craesbeck, 1648; y esta en pag. 95; el marques habia escrito: xun punto che in astratto si figura indivisibile, in concreto si divide in parti; su pud dividere in infinitow (V. Malvezzi, I Tanquinio superbo, in Macerata, heredi di Pietro Salvioni \& Agostino Grisei, 1632, pág. 5)

II V. Malvezzi, Il Romulo, ed. cit., pág. 8-9. 
de la obra y el pensamiento del autor. La lectura de Tácito se encarna en una sensibilidad nueva, y nueva, incluso, respecto a Justo Lipsio. Virgilio Malvezzi quiere ser la alianza entre la tradición retórica y la nueva ciencia.

La tensión entre esos términos se palpa en su estilo literario, que se suele comparar con el de Lipsio y los autores idolatrados por el humanismo erudito: Séneca, Tácito, Plinio el Joven. No es fácil calibrar la característica básica del estilo de Lipsio ${ }^{12}$, mientras que el repaso detenido de Epistolica institutio pone de relieve su preferencia térica por la versatilidad plautina (meo comico) y la elegancia de Plinio el Joven, cuyo cercano seguimiento sí es muy visible en su epistolario. Sus críticos le echaron en cara el abandono del paradigma ciceroniano (Tullianum tu non esse), crítica que responde recordando que en varias latitudes europeas su estilo era la norma actualizada de la latinidad. Lo que era cierto, como algunos de los estudios más recientes han puesto de manifiesto ${ }^{13}$, ampliando las clásicas intuiciones de Croll ${ }^{14}$. El laconismo de Malvezzi está pensado sobre exigencias muy paralelas, pero incorpora novedades. No se trata ahora tanto de romper con el ciceronianismo - percibido ya como anticuado-, cuanto de construir un clasicismo lacónico cuya principal novedad consiste en que Tácito ha pasado a un primer plano, desplazando la propuesta múltiple de Epistolica institutio. Se reelabora, además, el concepto de perspicuitas, que Lipsio todavía reivindica como elemento rector ${ }^{13}$. Puente esencial de esa evolución debieran ser sin duda obras como De laconismo sintagma (1609) de Ericius Puteanus, donde las más discutidas características de la prosa lacónica - la concentración del sentido, la oscuridad como paradigma didáctico - aparecen enaltecidas $^{16}$ y el estilo lacónico comparado con la perfecta geometría de la línea recta euclidiana ${ }^{17}$ y con la eficacia expresiva ( $«$ Verbis parco, re ostendam» ${ }^{18}$ ); en fin, el mismo estilo enervante del aragonés ya se perfila en la prosa de Puteanus. Piénsese cuánto debió contribuir a ello la importancia de la Retórica aristotélica, e incluso del mismo estilo del Estagirita, tal alabado en los prólogos gracianescos ${ }^{19}$. Y así, desde el mismo prólogo de los Discorsi sopra Cornelio Tacito,

12 En la interpretación clásica de Ch. Nisard, Le triumvirat littéraire XVle siecle : Juste Lipse, Joseph Scaliger et Isaac Casaubon, Paris, 1852, pag. 144, nos recuenda que oscila entre Plauto, Seneca y Plinio el Joven, conclusion que salta a la vista en la loctura de Epistolica institutio.

${ }_{13}$ C. Backvis, «La fortune de Juste Lipse en Polognew, en A. Gerlo, ed., Juste Lipse (1547-1606), Université Libre de Bruxelles, 1988, págs. 37-50, y en esp. pág. 45, a propósito del estudio de Barbara Otwinowska, cuyo libro no he podido ver.

14 M. W. Crolu, Style, Rhetoric and Rhythm, Princenton, New York, 1966, esp. phgs. 7-44.

is Iusti LIPSI, Epistolarum centuriae duae. Epistolica Institutio, in officina Hug. A. Porta, Lugduni, 1396, p. 18 y 24 de la Epistolica instizutio.

16 Erici Puteani, De laconismo sintagma, Lovanii, in officina typographica Gerardo Rivii, 1609, una continua exaltación de la densidad conceptual de la prosa: «Atque ut magnum nomen pauci nummi faciunt ac diluunt, si boni: sic magnum sensum pauca verba, si bonaw (pág. 45). Nótese en nuestra parca cita que ya late completo el estilo de Gracián.

17 Ob. cit., pag. 27: «Lineam roctam geometrae definiunt, quae in duo puncta brevísima est: sic recta illa orationis norma, quae brevissimis paucisimisque vertorum spatiis extensa estw.

18 Ob. cit., pag. 48.

19 Vtase la exposición tradicional de Nonden, Die Antike Kuntprosa, Teubner, Stuttgart, 1958, II, pags. 773-795, asr como G. Highet, The Classical Tradition, Oxfond University Press, London, 1967, pags. 322-354. Más sugerente A. Egido, La rasa del silencio. Estudios sobre Gracian, Alianza, Madrid, 1996, pags. 17-47. 
la oscuridad literaria, el proponer al lector una tarea de desciframiento, funciona ya explícitamente como motor de la prosa didáctica ${ }^{20}$. Apología del estilo que hermanando Aristóteles y Séneca reaparece en los prólogos de Baltasar Gracián.

Y esa tensión se trasluce también en otra de sus características básicas: notable proximidad al pensamiento de Machiavelli. El hecho ha sido reconocido desde hace tiempo en la famosa tesis de Toffanin ${ }^{21}$, algunos de cuyos aspectos merecen matizarse parcialmente, enriqueciendo, si cabe, una reflexión que resiste el paso del tiempo. Malvezzi constituye un atento seguidor de Machiavelli ya en los Discorsi, pero esa relación da un salto cualitativo en obras posteriores, y el florentino aparece directamente citado y alabado. De un Tácito que se supone usado a modo de máscara, en Il Tarquinio superbo pasamos al uso directo del florentino. Esta perspectiva incorpora otro problema que aquí tan solo enunciaré. Y es que la lectura de los comentadores de Tácito, y en especial en Virgilio Malvezzi, evoca el estilo de $1 l$ principe. Como se recordará, la obra maestra del florentino está escrita en un estilo muy particular, ajeno a la norma ciceroniana, pero cercano a usos cancillerescos ${ }^{22}$. Ese origen le proporciona una desusada fuerza literaria: periodo breve, incisivo, analítico, tú impersonal, imágenes fuertemente plásticas; los Discorsi de Malvezzi constituyen a trechos un voluntario homenaje a la inclinación analítica del florentino. Lo que viene a significar que los escritores al estilo lacónico podían utilizar directamente a Machiavelli - sin citarlo, claro está - sin alterar la forma de sus expresiones, cuanto menos su pensamiento. Probablemente no deba subrayarse la importancia estilística de $l l$ principe para entender el laconismo seicentista, pero sí habrá que tener en cuenta ese coqueteo literario como otro de los puentes que conduce desde la prosa de Justo Lipsio o incluso desde Epistolica institutio al tan remarcado apego a la prosa de Cornelio Tácito. Más importante, quizá, es el seguimiento conceptual. La prosa de Malvezzi está cuajada de conceptos maquiavelianos, ya presentes en los Discorsi, muy visibles en Il Romulo, y que se generalizan en Il Tarquinio superbo. Veamos algún ejemplo entre una cosecha realmente copiosa: el concepto de necesitd maquiaveliano («los mayores ejemplos para la venganza son la necesidad o la utilidad $»^{23}$ ), la censura del uso antipolítico de la violencia («las crueldades que no

20 II gusto poi che si riceve dal modo di Tacito, consiste prima, nello stile laconico... de insegnamento... l'oscurita sua da grandísimo gusto a chiunque affadigandosi ne trova el vero senso, giudicancolo parto del propio inteletto» (Discorsi sopra Cornelio Tacito, Marco Gianini, Venetia, 1622, Prologo, s. pág.).

${ }_{21} \mathrm{G}$. Toffanin, Machiavelli e il 'Tacitismo'. La 'Politica storica' al tempo della controriforma, Guida Editori, Napoli, 1972 (1“ ed. Padova, Draghi, 1921), y en España E. Tiemo Galván, «El tacitismo en las doctrinas politicas del Siglo de Oro», Anales de la Universidad de Murcia, 1947-1948, págs. 895-989, J. A. Maravall, «La corriente doctrinal del tacitismo político en Espana», Estudios de Historia del Pensamiento Espariol, Serie Tercera, págs. 77-105 y B. Antón, El tacitismo en el siglo XVII en Esparia. El proceso de 'receptio', Universidad de Valladolid, Valladolid, 1991, págs. 117-120.

22 F. Chabod, Escritos sobre Maquiavelo, Fondo de Cultura Económica, Mexico, 1984, y G. Inglese, «ll principe (De principatibus) de Niccold Machiavelliw, en A. Assor Rosa, dir., Letteratura italiana. Le Opere. I. Dalle origine al Cinquecento, Binaudi, pags. $930-932$

${ }^{3}$ Obras del marqués de Malvezzi, ed. cit., pág. 96r. 
sirven al imperio son furiosas» ${ }^{24}$ ) que recuerda tan de cerca el ejemplo de Agatocles en el capitulo VIII de Il principe, como el uso de giros comunes para ideas identicas ${ }^{25}, 0$, en fin, la reaparición de imágenes famosas de la obra del florentino, como la de terraplenes o diques que en el capítulo XXV de Il principe describen las medidas que se oponen al juego ciego de la fortuna ${ }^{26}$. En otras ocasiones se refiere directamente a Machiavelli llamándolo sabio en referencias demasiado paladinas como para pasar desapercibidas. Más importante todavía es documentar pilares básicos del pensamiento del florentino: la filosofía de la historia, su naturalismo filosófico, su pesimismo antropológico. El dinamismo intrínseco de la historia se formula en expresiones muy paralelas a la del mismo Machiavelli: «El que en las formaciones de las repúblicas constituye la mejor forma, no constituye la más durable: cuando se ignora el caminar más arriba y no se puede parar en un indivisible, es necesario volver a bajar, y en esta acción sucede muchas veces el precipicio" ${ }^{27}$. La cita resume la idea de una dinámica histórica continua que no permite las situaciones de estabilidad, y no por causas contingentes, sino por la misma naturaleza de los acontecimientos históricos, doctrina que aparece en casi cada página de Machiavelli, pero cuya formulación más acabada se halla en Discorsi, I, 6 («Ma sendo tutte le cose degli uomini in moto, e non potendo estare salde, conviene che le salghino o che le scendino; $e$ a molte cose che la ragione non $t$ 'induce, $t$ 'induce la necesita» ${ }^{28}$ ). Lo mismo sucede con el naturalismo del florentino: «No son los hombres los que constituyen las repúblicas, ni los principados, sino una cierta naturaleza o fuerza del interés que, aunque no conocida, no les da lugar a la quietud hasta que les conduce a aquella parte donde tienen mayor proporción, al modo que les sucede a los elementos, que sin noticia del lugar adonde caminan, guiados de su natural instinto, no se aquietan hasta que llegan a aquella parte que, aunque les era natural, la ignoraban. No para el agua en su propia esfera; y los pueblos, en su forma natural, son muy fáciles al gobierno ${ }^{28}$. En fin, para terminar con el comentario de Malvezzi, notemos que es difícil proponer que las

24 tbid., pág. 96v.

25 «Si los hombres fueran como debían, de necesidad habfiamos de tratar con ellos como se debe; pero los cuerpos corrompidos no apetecen los manjares sanos. Los advertidos nunca seran engafiados por creer poco, y los incautos errarán siempre creyendo mucho» (ed. cit., pág. 116v). La cita recuerda un famoso pasaje del capitulo XVIII de $l$ principe: $\propto \mathrm{E}$ si li uomini fussino tutti buoni, questo precetto non sarebbe buono: ma perche e'sono tristi e non la osserverebbono a te, tu etiam no l'hai a osservare a lorow (G. Inglese, ed., N. Machiavelli, Il principe, Einaudi, Torino, 1995, XVIII, 9, pág. 117.)

20 "En las ciudades libres, si los grandes tienen magistrado, son odiosos al pueblo, gusta de verlos humillados, y no advierte que son terraplenos o diques, que, si impiden la vista, reparan las inundaciones" (ed. cit., págs. 119r-v).

${ }^{27}$ Ed. cit., pag. 129r-v.

24 G. M. Anselmi e C. Varotti, eds., N. Machiavelli, Le grandi opere politiche. II. Discorsi sopra la prima Deca di Tto Livio, Bollati Boringhieri, torino, 1993, pág. 50.

29 Bd. cit., pág. 130, recuerdo muy paralelo de Il principe, VII, 4, ed. cit.,; $\star D i$ poi glo stati che vengono subito, come tutte l'altre cose della natura che nascono e crescono, non posso avere le barbe e correspondenzie lorow. 
características aludidas - la nueva ciencia, Machiavelli, la modulación del laconismo - no están relacionadas, que aparecen, simplemente, porque sí en una extraña mescolanza. Jorge Luis Borges recordaba en un comentario clásico que los tersos períodos lacónicos del Marco Bruto querían emular la exactitud de las matemáticas. Recogiendo el guante, bien podríamos preguntarnos si la acentuada fragmentación lacónica no quiere ser, entre otras cosas, una metáfora de la visión corpuscular de la realidad física que se va imponiendo lentamente al pensamiento de Galileo. $O$, incluso, si la pujanza de Machiavelli no corre paralela a la de Copérnico.

Los extremos que configuran esta poética aparecen a poco que se enfrenten los textos, y están ya presentes en los Discorsi sopra Cornelio Tacito, si bien encaramados todavía sobre el comentario del historiador latino, que apenas pasa de contingencia que incita a la reflexión, ya que todavía no al estilo. Los Discorsi enuncian en su prologo una pequera poética del laconismo, pero ni la estructura, ni el estilo recuerdan obras posteriores. El marqués busca su camino, y lo encuentra en Il Romulo: el salto cualitativo de un nuevo cauce literario. Desde un principio; se nos presenta como un modelo de hombre extraído de la lectura histórica («scriverò più dell'huomo, che di cotest'huomo»" ${ }^{30}$. La expresion de esa axiologia de base maquiaveliana toma el sustantivo héroe como uno de sus emblemas favoritos, tanto en Il Romulo ( $\ll$ Hà il principe un non sè che più chell'huomo, nella maestà del volto; ne gl'angioli che lo difondono, nelle stelle che gl'influiscono. Alcuni gli diede nome d'heroe, la verità lo chiamo Dio.... ${ }^{31}$ ), como en Il Tarquinio superbo ( LLa melancolía, que no es la hez, sino la flor de la sangre; la que no es carbon, sino una piedra preciosa, es la que produce los héroes; porque viviendo tan vecina la locura, conduce los hombres a aquel estado mayor, de cuyos términos no se da pasajes, y dentro de los cuales se extiende toda la virtud del saber humano ${ }^{32}$ ). El héroe, uno de los conceptos seminales de Gracián, surge naturalmente de la prosa malvezziana, lo que es todavía más evidente en la tipografía de las ediciones italianas de Malvezzi - y en su seguimiento las traducciones españolas-, que imprimen 'Héroe' siempre con mayúsculas. Ahí podía leer Baltasar el título de su primera obra desde principios de los años treinta.

Ese tipo de prosa fue el que sin duda recibió una espléndida acogida en la corte de Madrid a lo largo del año treinta. Uno de sus astros literarios y, en ese momento, estrecho colaborador del Conde-Duque, Francisco de Quevedo, se embarco de inmediato en su traducción, cuyas aprobaciones firma en agosto del año treinta y uno, y sin solución de continuidad comenzo la redacción de su Marco Bruto, admirable ejercicio literario y fiel reflejo de las formas lacónicas ${ }^{33}$.

30 V. Malvezzi, Il Romulo, ed. cit., pág. 9, y Quevedo en ed. cit., pág. 47: «escribire más del hombre que de tal hombrew.

${ }_{31}$ V. Malvezzi, Il Romulo, ed. cit., pág.' 18, y Quevedo, ed. cit., pág. 52: *Tiene el príncipe un no sé qué más que hombre en la majestad del semblante, en los ángeles que le defienden, en las estrellas que le influyen. Algunos le dieron nombre de heroe, la verdad lo llamó Dios».

32 Obras, ed. cit., pág. 122v.

33 A. Martinengo, El «Marco Bruto* de Quevedo: una unidad en dindmica transformación, Peter Lang, Bern, 1968. 
Podemos pensar que su traducción debió abrir paso a la moda lacónica en la corte; pronto se convierte en un estilo en boga: varios escritores de la corte se enzarzan en la creación de obras políticas y biográficas en directa emulación del italiano ${ }^{34}$. El hecho nos permite valorar la extraordinaria sensibilidad y capacidad de reflejos de Quevedo si comparamos cronologicamente su traducción con todas las restantes, todas posteriores a la suya, $y$, paralelamente, con otras formas literarias de la época -entremés, poesía, novela, prosa culta -, donde Quevedo impone sus maneras a los temas y a los géneros a despecho de casi todos sus contemporáneos.

Otra cosa es el planteamiento ideológico. Probablemente Francisco de Quevedo debio ver en la prosa de Malvezzi todos los extremos que ya hemos citado, aunque parece que su lectura debio inclinarse por las caracteristicas literarias más que por la formulación ideológicas ${ }^{35}$. Que percibió con más complacencia la cercanía a Lipsio o a Tácito, que determinadas afirmaciones que esa prosa contenía. El Marco Bruto de Quevedo, y Quevedo mismo, es más, mucho más, que estas simples citas, claro está, pero me interesa subrayar su actitud ante algunos de los giros comentados. En más de una ocasión, el Marco Bruto parece inclinarse por amonestar la prosa de Malvezzi. Se preocupa expresamente de polemizar contra el elogio de la geometría («no fue proporción de la geometria, sino estudio de la prudencia», «el que dijo que las virtudes consistian en medio, no consideró el medio de la geometr(a, sino el de la aritmética) $\left.{ }^{36}\right)$, o -de forma más esperable - exhibe su menosprecio de la fortuna («Arruinan a un monarca los malos consejeros, y culpan a la fortuna ${ }^{37}$ ), mientras que el sol ilumina buen trecho del texto sin conocer manchas. Incluso el recurso legítimo a la violencia para defender a la república se encuadra bajo el férreo predominio de la Providencia; el mismo uso de la ciencia nos recuerda - por contraposición - que tanto en Gracián como en Saavedra ya aparecen de tarde en tarde manchas solares y estrellas envejecidas.

A remolque de Francisco de Quevedo, comienza a principios de los años treinta a escribir Diego de Saavedra Fajardo ${ }^{38}$, que publicará lo que hoy tenemos por su obra mayor, las Empresas polfticas, en 1640 (edición revisada en 1642). Para nuestro objeto actual nos interesa el comienzo de la Empresa 60 . Su mote

34 J. Garcfa Lopez, «El estilo de una corte: apuntes sobre Virgilio Malvezzi y el laconisno hispano», Quaderns d'Italia, 6 (2001), pags. 155-169.

35 Sobre la influencia de Malvezzi en Quevedo, véase C. Vafllo, «La anotación y edición de la Vida de Marco Bruto», La Perinola, 4 (2000), pags. 394-414, e id., «Fuentes antiguas y modernas escondidas en La vida de manco Bruto de Quevedon, en G. Grilli, ed., Modelli. Memorie. Riscritture, Istituto Universitario Orientale, Nápoles, 2003, págs. 221-238, asi como M. Blanco, - Ouevedo lector de Malvezzix, La Perinola (en prensa); agradezco a la profesora Mercedes Blanco el amable envio de su trabajo durante la redacción de esta líneas.

36 Las dos citas en F. de Quevedo, Obres, Atlas, Madrid, 1946, pag. 1344.

37 F. de Quevedo, ed. cit., pag. 148".

33 Doy por hecho que Saavedra no es el autor de la primera redacción de República literaria; cfr. A. Blecua, «Las Repúblicas literarias y Savedra Fajardo», El Crotalón. Anuario de la Filologia Espafiola, I (1985), pp. 67-97, y J. Garcia Lopez, «Los manuscritos de la segunda redacción de Republica literaria», Boletín de la Real Academia Espantola, LXXXII (2003), págs. 79-111. 
reza $O$ subir o bajar y le acompaña el dibujo alusivo donde una saeta muestra la necesidad de tomar uno de los dos caminos que resume el mote: o subir o bajar. Ahora bien, como ya hemos visto en el caso de Virgilio Malvezzi, se trata de la traducción directa de una expresión maquiaveliana («conviene che le salghino o che le scendino»). No deja de ser extremadamente llamativo que el mote de una de sus principales empresas, sea la traslación literal de un giro que resume de maravilla la filosofía de la historia del florentino. $Y$ además, lo interesante del caso es que Saavedra cite a Machiavelli de forma literal, cosa que no había hecho Malvezzi al recordar ese lugar. Don Diego escribía en un estilo lacónico que era la moda cortesana, pero evocaba de memoria lecturas de los Discorsi de Machiavelli. Y esas expresiones encuentran naturalmente un lugar en su prosa lacónica, puesto que ya eran expresiones lacónicas en su origen. Si seguimos leyendo el comienzo de la empresa, nos topamos con una comparación matemática de origen geométrico («como los ángulos en el círculo, que pasa el agudo a ser obtuso sin tocar en el recto ${ }^{39}$ ) que nos recuerda la poética de la prosa malvezziana. Pero hay más. Apenas unas líneas más adelante encontramos sin buscarlo en naturalismo maquiaveliano en la comparación de las repúblicas y los principados con vegetales («No son las monarquías diferentes de los vivientes o vegetables. Nacen, viven y mueren con ellos, sin edad firme de consistencia, y así son naturales sus cardas»" 9 . Si observamos el margen de las antiguas ediciones de las Empresas políticas es admirable comprobar cómo don Diego se desvive por indicar las fuentes, cómo se parapeta tras todo tipo de citas. Pero ni Hipocrates, ni Aristóteles, ni Cicerón pueden venir en su apoyo sino muy tangencialmente. Esos autores solo contienen de forma harto imperfecta y marginal lo que en realidad quiere decir Saavedra, que es lo mismo, literalmente lo mismo que nos dice Machiavelli en los Discorsi: «conviene che le salghino o che le scendino», es necesario 'o subir o bajar'.

Citas encubiertas del florentino en la prosa de Saavedra que nos van de perlas para entender los caminos de la influencia maquiaveliana. Exceptuando quiź́ a Quevedo -donde tampoco es diff́cil pergefiar alguna cita- ${ }^{41}$, esa influencia no se basa en una serie de consejos estridentes que chocan con la moral tradicional, cosa que serfa inaceptable, por supuesto, dado que el providencialismo continúa vivo en el mundo intelectual de Saavedra. Y ni siquiera Machiavelli puede ser utilizado tal cual, puesto que en el fondo pertenece a otra epoca, y muchos problemas nuevos no encuentran respuesta en su prosa. Pero la misma evolución histórica - ruptura religiosa y guerras de religión, Guerra de Treinta Años, pesimismo generalizado - permite que aquí y allá se cuelen aspectos del pensamiento maquiaveliano que conduce a idénticas posiciones a poco que se

${ }^{39}$ S. Lopez Poza, ed. cit., pág. 705.

1 S. Lopez Poza, ed. cit., pág. 706.

41 \&Lagrimas contrahechas se derraman por los padres, hijos y mujeres perdidos, y solamente alcanza lágrimas verdaderas la pédida de la hacienda» (F. de Quevedo, Obras, ed. cit., pág. 132, en el prologo del Marco Bruto), recuerdo de un famoso lugar de $l l$ principe, XVII, 14 («li uomini sdimenticano pia presto la morte del padre che la perdita del patrimoniow), cfr. G. Inglese, ed. cit., pág. 111-112. 
los desarrolle, e implican, tarde o temprano, un providencialismó atenuado. El siglo XVII comienza su andadura como el anterior, demonizando al florentino, pero lentamente reconsidera sus posiciones. Y ello se materializa en la frecuencia con que aparecen tres elementos básicos: una filosofía de la historia constitutivamente dinámica en opciones excluyentes ('o subir o bajar'), el naturalismo político y, más generalizado todavía, el pesimismo antropológico.

Cuanto hemos visto se reproduce en el texto de Gracián. Como emblema de su origen vale el título de su primera obra, El héroe (1637), un sustantivo que ya habia utilizado Malvezzi y sus traductores como cifra del modelo de hombre que nos propone Il Romulo. Por otra parte, más de una vez, Gracián parece estar introduciendo variaciones en giros que podemos documentar sin grandes esfuerzos entre la prosa de Malvezzi. En El polftico, por ejemplo, encontramos alguno ( «no tanto cuerpo de su historia, cuanto alma de su política» ${ }^{42}$ ) que recuerda muy de cerca el elogio de Il Romulo en el prólogo de Quevedo («los pasados fueron historiadores de su vida, nuestro autor de su alma ${ }^{43}$ ). Gracián podría haber leído a Malvezzi en la traducción de Quevedo, puesto que, además, esa cita la recuerda con delectación, como ocurre en el elogio de los historiadores en el remate de su Primor XI («Hay gracia de historiadores... Retratan, no los aciertos de la naturaleza, sino los del alma» ${ }^{44}$ ).

Pero si la semilla de estas primeras obras de Gracián lo constituye esta prosa de finales de los años veinte, merece de por sí una especial consideración, puesto que Gracián fue ya en su tiempo, y lo sigue siendo, el maestro de la prosa lacónica. Y es que el genial aragonés somete al estilo lacónico a su máxima productividad, modulando hábilmente sus posibilidades, ignorando los perfiles genológicos que lo vieron nacer. Por ello, sin prejuicio de documentar ese origen, puede también acotarse un inventario de variaciones, que si no subidas en número, sí delatan una cuidadosa reflexión estética sobre la biografía lacónica. Quizá la principal variante consiste en prescindir del entramado histórico para centrarse primordialmente en el planteamiento axiológico. Las biografías laconicas se vertebran sobre una historia comentada en el plano político y moral: la historia lineal deviene doctrina en el comentario. Gracián prescinde de esa linealidad. Está presente, pero el discurso moral dosifica aquí y allá sus ejemplos, disponiéndolos como en centros de interés; la iniciativa ya no corresponde a la historia, sino a la ética. Su discurso alcanza asi, a priori, una universalidad que no tenía la biografía lacónica en origen; desde un principio, la biografía gracianesca no es biografia, sino ejemplaridad modélica. Y sin embargo, esa universalidad esconde un rebajarse a un plano más humano, tanto en el lenguaje, que acoge una selección léxica que parece querer modular la gravedad lacónica, como en el planteamiento ideológico, en cuanto busca demorarse en un modelo

42 M. Batllori, ed., B. , Obras completas, Atlas, Madrid, 1969, pág. 276.

${ }^{4} \mathrm{C}$. Isasi, id. cit., pág. 109, prólogo de Quevedo A pocos.

4 L. Santa Marina, ed., B. Gracián, El héroe. El discreto. Ordculo manual y arte de prudencia, Planeta, Barcelona, 1984, y véase ahora la excelente edición de A. Bernat y A. Madrotal, eds., El héroe. Ordculo manual y Arte de Prudencia, Castalia, Madrid, 2003, y la cita en pág. 126. 
que no se reduce al del príncipe, sino que es ejemplo para el hombre cortesano. Una ética para la vida social fundada en el pesimismo antropológico.

Pero esa es quizá la novedad esencial entre una montaña de jugueteos formales. Su prosa no abunda en comparaciones matemáticas, aunque muchas veces la idea de centro, muy socorrida, incluye la idea de circunferencia. Tampoco frecuenta las metáforas musicales a las que fueron tan aficionados autores como Saavedra Fajardo. Sin embargo, pese a esta parquedad, topamos con sorpresas. No duda, por ejemplo, en utilizar como materia literaria la polémica de las manchas solares ( al mayor lucimiento, que es el del sol, achacaron vejeces los filosofos y descaecimiento el brillars ${ }^{45}$ ) lo que no excluye una esperable mentalidad aristotélica en sus ideas físicas («no hay estrella fija de la luna acá»). Es curioso en todo caso, que Gracián no parece muy disgustado con lo que dicen esos 'filósofos' que achacan 'descaecimientos' al sol, y solo un ligerísimo matiz de censura se adivina en sus palabras. Pero si de las referencias a las ciencias de la época pasamos a la filosofía de la historia nos llevamos una sorpresa mucho mayor, puesto que también él recuerda el famoso lugar de Machiavelli donde los escritores lacónicos de la época leyeron, como en un emblema, la naturaleza dinámica de la historia: «No hay dicha, porque no hay estrella fija de la luna acá; no hay estado, sino una continua mutabilidad en todo. $O$ se crece 0 se declina, desvariando siempre con tanto variars ${ }^{46}$. Otra vez la expresión retoma un estilo plenamente lacónico que no necesita ni siquiera violentar la formulación del florentino («che le salghino o che le scendino»). Y con todo, no podemos asegurar totalmente que lo haya utilizado directamente, puesto que, por ejemplo, podría haber elaborado su expresión a partir del mote de la Empresa 60 de Saavedra, y en todo caso proponer esa influencia no sería novedad alguna, puesto que ya Maravall había mostrado con lujo de detalles que en la corte de Felipe IV Machiavelli bullía por todas las esquinas ${ }^{47}$. El pensamiento maquiaveliano es el ruido de fondo del siglo 'barroco', un siglo «maquiavélico a su pesan»" Por otra parte, la misma biografía lacónica es ya de por sí un fiel prontuario de citas. Sobre ese fresco de fondo, creo que puede sostenerse un conocimiento más detallado. A esa conclusión, nos inclinan elementos como la imagen de la fortuna como una mujer en $E l$ héroe, que - se ha dicho- está en los Detti. En efecto: y probablemente en cien sitios más. Lo que no está en Botero es el jugueteo con la imagen: sabía muy bien de dónde venía, y lo que exactamente significaba. Pero, además, es evidente que el aragonés busca el cuerpo a cuerpo, necesita un oponente a su altura: no acaba de serlo Virgilio Malvezzi. La tensión de su estilo busca una diana precisa, sobre todo en su trilogía biográfica, pero muy visible en el Oráculo, y de ámbito cortesano, de amplia proyección; no se conforma con menos. Porque está claro que la

4s El Héroe, primor XVI, Renovación de grandeza; cfr. L. Santamarina, ed. cit., 34.

46 A. Egido, ed., B. Gracián, El discreto, Alianza, Madrid, 1997, pág. 298.

47 Véase anteriormente, $n .17$.

4 De acuerdo con la brillante expresión de J. Elliot, El Conde Duque de Olivares, Crítica, Barcelona, 1990, p. 416. 
relación apuntada no implica simple influencia, sino que una atención creciente a las obras de Machiavelli - después de las condenas tridentinas - constituye el contexto seminal, el mundo en el que se encuentra instalada la prosa de Gracián. A partir de ahí, exhibe una idiosincrasia casi diametralmente opuesta; a la mentalidad descriptiva del florentino, opone una normativa. La novedad estriba en la tortuosa convergencia de esos términos: las cosas han cambiado desde Rivadeneyra y Botero. La Providencia y la Fortuna están ahora en un ten con ten desusadamente igualado. Aquella ha perdido la inocencia de antaño, y ahora, caso por caso, dirime sus derechos: sabe que está obligada a ceder mucho para ganar mucho. Esa novedad es la que nos interesa en estas páginas. En ese estar al filo de la navaja, se dirime el sentido del héroe gracianesco.

No podemos, claro está, convertir un breve artículo en historia de un estilo. Gran parte de ella gira en torno a la asunción del estilo del aragonés por clasicismos posteriores. En un ir y venir entre'el Madrid rendido ante el marqués de Malvezzi y el Museo de Lastanosa; en el fondo, ya digo, una sorda lucha entre el aragonés y el florentino en la que es casi imposible decidirse. Sin embargo, puesto que hemos comenzado este recorrido con el héroe malvezziano, terminaremos también con él estas líneas. Ejemplo interesante y singular de la apropiación de las formas gracianescas, y aun de la prosa lacónica en su conjunto, lo constituye el Atheneo de Grandesa de Joseph Romaguera ${ }^{49}$. Escrito en catalán a principios de los años ochenta («en Barcelona, en casa de Joan Jolis, al carrer dels Cotoners, any $1681 »)$, ha llamado la atención en especial por el elogio de la lengua catalana que encontramos en su prólogo ${ }^{50}$. En todo caso, la obra de Romaguera nos sigue mostrando la atracción de la biografía barroca a lo Virgilio Malvezzi, pero compenetrada con el maestro del estilo. De hecho, en la prosa de Romaguera hemos abandonado los anhelos iniciales del estilo y recalamos en su consideración meramente moralista. Y junto al seguimiento de las formas gracianescas una amalgama de estilos que recuerdan no sólo El héroe, sino también la literatura emblemática con algún aire de Saavedra Fajardo ( Catalana facundia ab Emblemas illustrada" nos dice ya en la portada). Josep Romaguera divide su obra en catorce Eminencias de sabor plenamente gracianesco, y las remata con un emblema comentado en prosa y en diferentes metros poéticos, lo que convierte su obra también en un personal cancionero. No creo equivocarme mucho si afirmo que Romaguera no parece manejar a Virgilio Malvezzi, pero recuerda muy de cerca la tersa prosa del aragonés. Incluso, algunos de los capitulos de su obra repasan de cerca los giros gracianescos. Asf ocurre, por ejemplo con la segunda eminencia ( Ostentarse a la coneixensa, neganse a la comprehencio»" ${ }^{51}$ que recuerda muy de cerca el comienzo del Primor Primero de El

4 Las citas por el facsimil de Josep Romaguera, Areneo de Grandesa, Lletra Menuda, Sueca, 1980.

so Cfr. F. Feliu, «Una lliço d'historria de la llengua literària. El pròleg a l'Atheneo de Grandesa de Josep Romaguera», Estudi General. Miscel.lania d'Homenatge a Modest Prats, 22 (2002), II, págs. 445. 465.

s1 Ed. cit., pág. 9. 


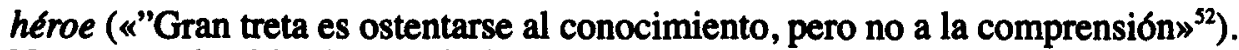
No sorprende el hecho en sí, sino la literalidad del trazado. Pero no se trata de acusación contra Romaguera, sino recuerdo de que el estilo lacónico siempre se extracta; lo hacía, por lo que parece, el mismo Lastanosa. Gracián mismo se extrae, glosa y comenta en el Oráculo; parece el destino de un estilo que se reproduce partiendo de minúsculas partículas de sí mismo, cual un organismo vivo. Ello nos permite hacer un tanteo de inventario entre sus seguimientos literarios. Comencemos por Saavedra, cuya inspiración parece evidente en el enfilamiento de sus catorce Emblemas cerrando cada Eminencia. Algunas de ellas recuerdan muy de cerca las Empresas políticas. Así, por ejemplo, el Emblema VII, donde un león aparece rodeado de diamantes en forma de estrellas («ab que lo coronat signe de leo, brodant sa gala ab 27 zodiacas lanteyuelas, o ennoblint sa pompa ab altres tantas joyas de fiscos diamants ${ }^{33}$ ) recuerda demasiado los dibujos de leones de las Empresas 45 y 99 de Saavedrat . O bien la «dolça sirena, hermosa Cloris entre estrados de zafirs» del Emblema XII ${ }^{55}$ parece inspirado en el que abre la empresa 78. Pero es especialmente el Emblema V, donde una figura humana se refleja equivocamente en una fuente redundando en lo engañoso de las apariencias y aplicado a Narciso como ejemplo de «murmuradora affectación ${ }^{36}$ en el mote Fallit imago, que recuerda demasiado el Fallimur opinione con que Saavedra abre la Empresa 46, aunque añadiendo ahí un elogio del pensamiento académico, es decir, escéptico ${ }^{57}$.

Pero si los recuerdos saavedrianos son muchos, más y mejores son los de Gracián. Y esto hasta el punto de llegar a la literalidad. Y asi, para empezar, la Eminencia III («Sacramentar afectes») nos trae a las mentes un conocidísimo giro gracianesco ( $* \mathrm{Si}$ todo exceso en secreto lo es en caudal, sacramentar una voluntad será soberania» ${ }^{\text {s8 }}$ ), mientras la Eminencia VI («Aspirar a la grandesa de primers) recuerda muy de cerca la Excelencia de primero del Primor VII de El héroe, o la Eminencia X («Antes de empeñarse, tantear la fortuna») recuerda también literalmente el Primor X de El héroe («Que el héroe ha de tener tanteada su fortuna al empenarse»), o, en fin, el titulillo de la Eminencia XI («Obtenir sinderesis y agudesa ab igual excellencia») recuerda muy de cerca trazos gracianescos del Oráculo manual ( $« D e$ la gran sindéresis» ${ }^{59}$ ) y el comienzo del Primer Primor con la metáfora microcósmica («Es lo racinal microcosmos subsint mapa de tota grandesa...»), mientras la Eminencia XII («Esmerarse en lo plausible, com en lo arduo dels empleos») se toma del Primor VIII («Que el héroe

52 L. Santa Marina, ed. cit., pág. 7.

53 Ed. cit., pág. 65.

34 S. Lopez Poza, ed. cit., págs. 540 y 1045 respectivamente.

ss Ed. cit., pág. 117.

s6 Ed. cit., pág. $42-43$.

57 S. Lopez Poza, ed. cit., pág. 545.

Ss L. Santa Marina, ed. cit., pág. 8

${ }^{99}$ L. Santa Marina, ed. cit., pág. 172. 
prefiera los empeños plausibles»). Esa literalidad salta en ocasiones los titulillos de las Eminencias para reproducirse en el recuerdo de expresiones muy queridas de Gracián («y fins humillarse a Mediterraneo asegura en la herculea boca lo Non plus ultra de sa profunditat ${ }^{60}$ ), reservadas para nombrar a Fernando el Católico («el Non Plus Ultra de sus heroicos reyes»), sino también en la reproducción de algunos párrafos. Entre varios ejemplos que podríamos aducir, véase el anteriormente recordado elogio de los historiadores:

Ateneo de Grandesa, pág. 127: «Aventatjas esta amable gracia ab la dels historiadors, estos retratan las prendas naturals, y las aquiridas, y reduint eloquents rasgos, à eterns caracters animan inmortalitat, y fins del envellit silenci saben resucitar Paralipomens, que ab plomas de Fenis aviven sa grandesa».

El héroe, ed. cit., pág. 28, «Hay gracia de historiadores también, tan de codicia cuan de inmortalidad, porque son sus plumas las de la fama. Retratan, no los aciertos de la naturaleza, sino los del alma.»

Como va dicho, Gracián realiza aquí una elegante variación sobre una expresión malvezziana que había potenciado Quevedo en su prólogo como cifra del héroe ${ }^{61}$. Pero no todos, sin embargo, son aparentes reproches, y menos contra Romaguera, que debía escribir en catalán en 1681 contra viento y marea. Es evidente su deseo de variación sobre el estilo magistral en la búsqueda de ejemplos antiguos y modernos o en algún que otro vocabulario que desborda por su modernidad el tratamiento que recibe en Gracián. Sea por una mayor apertura a determinadas novedades léxicas e ideológicas («Ingenios lo quimich ab lo elixir divino converteix en plata lo defectuos mercuri» ${ }^{62}$; «Lo matematich Euclides ${ }^{63}$; "Ostentà Arqchimedes ab geometrica demonstracid...." ${ }^{64}$ ) como por la perfecta comprensión del espacio estilístico en el que se mueve. Entre tantos otros, uno de los muchos aciertos de Baltasar Gracián como escritor no estriba únicamente en el elegante ductus de sus períodos, sino en una precisa elección léxica que conjuga la gravedad lacónica - por decirlo con sus propias palabras - con una sorpresiva humildad léxica, apuntando a una equilibrada sindéresis de extremos hábilmente conjugados. Romaguera vuelve sobre el procedimiento en varias ocasiones, y no sin éxito, rebuscando aquí y alli expresiones o metáforas ajenas al marchamo de lo exquisito o lo culto. El la de los que cantan, por ejemplo ( Pero que ab just compas pujà lo Apollineo Cor, los ecos de son aplauso al LA de sos canoros acentos, celebrant estas imperials primicias» ${ }^{65}$ ) o bien la metáfora del calafateo ( $\mathrm{AA}$ esta llum obra la comuna benevolencia en lo inferior, lo que lo violent alquitrd en la nau, defensa-la del aygua, y abrasa-la ab lo foch» ${ }^{66}$ ) 0 ,

\footnotetext{
* Ed. cit., pág. 13, y la expresión nuevo más abajo, pág. 102.

61 Vease anteriormente, n. 40.

62 Ibid.., pág. 19.

63 tbid., pág. 41.

4 fbid., pág. 69

os fbid., pág. 50, para la expresión cfr. Covarrubias.

os tbid, pag. 126.
} 
en fin, la comparación del ánimo con la escritura («Acostuma lo animo à pasar com lo paper, y se llegeix en la cara, lo que esta impres en lo cor ${ }^{67}$ ). Y muy especialmente cuando viene a llamar al discreto, al modelo de comportamiento propuesto en El héroe, nada menos que 'galateo español', demostrando su profunda comprensión de las intencionalidades que envuelven la gestación literaria de $E l$ héroe: «Pesar deu lo discret esta precisa joya, en lo curiós contrast del Galateo, al contrapes de la dignitat, $\partial$ del merit; pero a ont no trobara etiqueta que seguir à ditxo del Seneca de España, millor es pecar per carta de mes, que de menos» ${ }^{68}$.

Sin embargo, no puede decirse que el enemigo primordial de Romaguera sea Gracián, a quien sigue tan de cerca, y ni siquiera Saavedra, que recuerda en los dibujos de sus Eminencias. Lo que desequilibra su estilo es que a pesar de su desusada proximidad al aragonés, otras formas pujan por sus derechos y desmienten su cerrada emulación gracianesca. Cuando tras un recuerdo del «segàs Machavello» llama a la bizarría «rosicler notori de la generositat» o cuando amontona períodos condicionales, no ajenos a la pluma de Gracián, pero nunca de tan llamativa abundancia ( $«$ Esculpida ninfa ab indiferent aspecto, si favorable, Flora, si fastidiosa, Medussa, si risueña, Hebe, si esquiva, Dafne, que fugint dels discrets Apolos.... ${ }^{69}$ ), nos recuerda otro estilo muy de moda por entonces y que evita de todo punto el aragonés. Me refiero, claro está, al preciosismo que en muchas ocasiones desborda por completo en la pluma de Romaguera, y que convierte el seguimiento cercano de Gracián en una aparente incompresión de fondo, añadiendo exquisiteces gongorinas al caldo lacónico. El mismo Emblema XII (Pectora mulcet) acumula una sarta de preciosismos estilisticos escoltados por recuerdos gracianescos («hermosa Cloris entre estrados de zafirs, crespa rayos, brilla estrellas, neva espumas, anima rosas, ostenta corals, rescata perlas, y encant sos ecos, pasma, suspenan, y tiranizan ab mes donayre, que cuydado...ingeniosa inventiva de sos alumnos, sifra acolorida divisa, intims destinos de celebres empresas de molt heroes, sent aplauso universal de la florida eloquencia» ${ }^{70}$ ) que parecen fluctuar entre las Soledades («hermosa Cloris entre estrados de zafirs») y repuntes lacónicos del héroe gracianesco («"intims destinos de celebres empresas de moles heroes»).

La verdad es que Josep Romaguera no es lacónico o no quiere serlo del todo o quizá no sabe serlo, aunque la atracción de El héroe es evidente, y -curiosamente - es el encanto por esa obra de Gracián y el casi olvido de las restantes. Pero el Ateneo de Grandesa no está construido sobre el intento de usar la prosa lacónica en numerosas tonalidades retóricas - como es el caso de $\mathrm{El}$ discreto, por ejemplo-, sino en el de usar el catalán en el mayor número de registros posibles, desbordando la ejemplaridad lacónica y convirtiendo su obra casi diriamos en un desfile de posibilidades estilísticas -repetida en la numerosa variedad de metros poéticos - que nos sirve disfrazadas a la sombra ennnoblecedora de la prosa de Gracián. Nos recuerda otra vez, eso sí, el origen y la naturaleza biográfica de la prosa del aragonés.

\footnotetext{
67 tbid., pág. 19.

68 fbid., pág. 125.

6 fbid., pág. 88.

70 Ed. cit., pág. 116.
} 